\title{
Tolerance and Durability of Abacavir/Lamivudine (ABC/3TC) Containing Regimens: Results from a large French Prospective Cohort
}

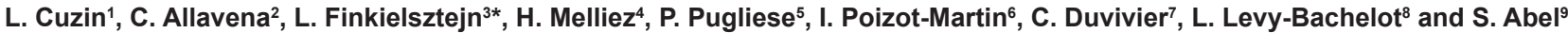

${ }^{1}$ Infectious Diseases Unit, Purpan Hospital, Toulouse, France

${ }^{2}$ Service de Maladies Infectieuses et Tropicales, CHU Nantes, France

${ }^{3}$ ViiV Healthcare, Marly le Roi, France

${ }^{4}$ Service Universitaire des Maladies infectieuses et du voyageur, Centre hospitalier de Tourcoing, France

${ }^{5}$ Pôle Infectiologie, Hôpital de l'Archet, Nice, France

${ }^{6} \mathrm{CISIH}$, CHU Sainte Marguerite, Marseille, France

${ }^{7}$ Groupe hospitalier Necker-Enfants Malades, Service de Maladies infectieuses et tropicales, Centre d'Infectiologie Necker-Pasteur, Descartes-Paris 5 University, Paris, France

${ }^{8}$ GlaxoSmithKline, Marly le Roi, France

${ }^{9}$ Service des Maladies infectieuses et tropicales, $\mathrm{CHU}$ de Fort-de-France, French West Indies

Dat'AIDS Cohort scientific committee: P. Enel, V. Obry-Roguet, O. Faucher, S. Bregigeon, A. Ménard, I. Poizot-Martin, (Marseille), B. Marchou, P. Massip, E. Bonnet, M. Obadia, M. Alvarez, L. Porte, L. Cuzin, M. Chauveau, M. Barone, I. Lepain (Toulouse), P. Pugliese, L. Bentz, C. Ceppi, E. Cua, J. Cottalorda, J. Durant, S. Ferrando, J.-G. Fuzibet, R. Garraffo, A. Leplatois, V. Mondain, I. Perbost, S. Pillet, B. Prouvost-Keller, C. Pradier, S. Pugliese, P.-M. Roger, F. Sanderson, V. Rahelinirina, E. Rosenthal, M. Vassallo, P. Dellamonica (Nice), C. Allavena, E. Billaud, C. Biron, B. Bonnet, S. Bouchez, D. Boutoille, C. Brunet-François, N. Feuillebois, T. Jovelin, O. Mounoury, P. Morineau, F. Raffi, V. Reliquet (Nantes), Y. Yazdanpanah, P. Choisy (Tourcoing), C. Duvivier, M.-A. Valantin, R. Agher, C. Katlama (Paris), A. Cabié, S. Abel, S. PierreFrançois, B. Liautaud (Fort de France).

\begin{abstract}
Background: Abacavir is considered as a potent and well tolerated drug but recent controversial data have raised questions concerning cardiovascular tolerability and virological efficacy in antiretroviral initial regimen with abacavir/lamivudine (ABC/3TC).

Methods: Patients were selected from the Dat'AIDS french prospective cohort if they were prescribed a regimen containing ABC/3TC free or fixed dose combination for the first time between 01/01/2004 and 31/12/2007 before HLA screening recommendation or routine usage. All causes of treatment discontinuation were recorded, as well as immuno-virological and clinical data during follow-up.

Results: Among the 1704 patients included in the study (male 69\%, mean age 43 years) 407 (24\%) were antiretroviral naïve, $696(41 \%)$ had viral load (VL) below detection on ARV treatment (switch), and 601 (35\%) were on treatment with detectable VL (failure) at time of $\mathrm{ABC} / 3 \mathrm{TC}$ initiation. Overall 565 patients $(33 \%)$ discontinued ABC/3TC combination during follow-up, among them $26 \%$ have used $A B C$ in the next regimen. Reasons for discontinuation were intolerance in $14 \%$ of the cases - including suspected hypersensitivity (HSR) in $7 \%$ of the overall population - treatment failure in $20 \%$, and other causes in $39 \%$. The median time to treatment discontinuation was 52 months for the overall population. After 2 years, the probability of receiving ABC/3TC was at $62 \%, 77 \%$, and $60 \%$ respectively for the defined groups. Finally, the $\mathrm{VL}$ on treatment was below detection for $86 \%, 90 \%$, and $71 \%$, respectively.
\end{abstract}

Conclusion: In this population $\mathrm{ABC} / 3 \mathrm{TC}$ containing regimens were maintained with virological success for more than 2 years. Tolerance issues including HSR were the main reason for early discontinuation.

Keywords: HIV; Abacavir; Lamivudine; Antiretroviral therapy; Durability; Tolerance

\section{Introduction}

Abacavir (ABC) has been used as part as combined therapy (cART) in human immunodeficiency virus type 1 (HIV-1)-infected patients since 1998 and thus has contributed to the large improvements in patients' health and survival [1]. Fixed drug combination with lamivudine (3TC) provided benefits in adherence to treatment by reducing the daily pill burden. Severe cases of drug related hypersensitivity were described with a frequency of 4 to $7 \%$ [2], later associated with a positive HLA-B ${ }^{\star} 5701$ aplotype [3], allowing efficient screening of 'at-risk' patients. $\mathrm{ABC}$ has been associated with an increased risk of myocardial infarction (MI) in observational studies [4] but more recently, this has been refuted in further analyses [5,6]. Although $\mathrm{ABC}$ has been proven potent in many studies, it may be less effective in patients with baseline viral load over $5 \log _{10}$ copies/ $\mathrm{mL}$ and some expert guidelines have limited its use, despite European and US health authorities have not limited $\mathrm{ABC} / 3 \mathrm{TC}$ prescription in high viral load [7]. However, every antiretroviral drug (ARV) has its own profile of tolerability and the choice of treatment should always be personalized, taking into account the overall absolute risks and benefits for long-term treatment. Many physicians believe that abacavir is a potent drug and long term tolerance has to be documented.

In order to describe tolerance and durability of cART based on the combined $\mathrm{ABC} / 3 \mathrm{TC}$, we searched our large prospective cohort for

*Corresponding author: Laurent Finkielsztejn, Medical Department, ViiV Healthcare, 100 route de Versailles, 78163 Marly-Le-Roi Cedex, France, Tel: +33139176906; E-mail: Laurent.I.finkielsztejn@viivhealthcare.com

Received July 28, 2011; Accepted January 26, 2012; Published January 30, 2012

Citation: Cuzin L, Allavena C, Finkielsztejn L, Melliez H, Pugliese P, et al. (2012) Tolerance and Durability of Abacavir/Lamivudine (ABC/3TC) Containing Regimens: Results from a large French Prospective Cohort. J AIDS Clinic Res S1:019. doi:10.4172/2155-6113.S1-019

Copyright: (c) 2012 Cuzin L, et al. This is an open-access article distributed unde the terms of the Creative Commons Attribution License, which permits unrestricted use, distribution, and reproduction in any medium, provided the original author and source are credited. 
$\mathrm{ABC}$ naïve patients who have been receiving this combination as part of one of their regimens.

\section{Materials and Methods}

Information was collected from 7 large HIV reference centers in France (Fort-de-France, Marseille, Nantes, Nice, Paris, Toulouse, and Tourcoing). These hospitals maintain prospective cohorts of all HIV1 infected patients who seek care in the centers and provided written informed consent. The cohorts are implemented via an electronic medical record (EMR). The patients enter the cohort when they seek care in one of the centers regardless of their HIV disease history and all previous clinical events as well as therapeutic history are collected with appropriate dates. The EMR collects demographic details, clinical events, antiretroviral history, viral load and CD4 cell count data for patients at regular 3-6 month intervals during routine clinical assessment. This system allows use of the databases with minimal delay, limited to automatic and manual quality controls performed before any analysis [8].

For the purpose of this study, we selected adult HIV-1 infected patients' naive for $\mathrm{ABC}$ who have been receiving for the first time $\mathrm{ABC}$ and 3TC either as a fixed-dose combination or a separate component between January 2004 and December 2007 as part of their regimen, irrespective of their previous therapeutic history. The patients could have received 3TC. ABC/3TC combination may be used either as part of the first antiretroviral regimen (naïve patients), as part of a switch strategy in patients with HIV-1 RNA level (VL) below 50 copies $/ \mathrm{ml}$ (switch) or, as part of a salvage regimen in patients with a previous failing regimen (failure). The ABC/3TC fixed-dose combination has been available from January 2005.

We recorded demographical (age, sex), biological (all available CD4 and VL values during follow up, hepatitis co-infections), therapeutic (treatment history, ARV drugs prescribed in association with $\mathrm{ABC} / 3 \mathrm{TC}$ ) and clinical data (duration of known infection, all major clinical events - including pregnancies - before or during treatment, death with date and cause if any). In case of $\mathrm{ABC} / 3 \mathrm{TC}$ discontinuation, the date and cause were recorded. The cause recorded in the data base is coded at the time of discontinuation by physician who makes the decision with the patient, following a limited list of items. Causes of discontinuation were classified as intolerance (any adverse event leading to discontinuation), virological failure (detectable VL) or other cause (non-adherence, pregnancy, inclusion in a clinical trial, as examples). If the VL was greater than 50 copies $/ \mathrm{mL}$ at the time of discontinuation, the cause was considered as virological failure whatever the recorded cause in the database. At the time of first prescription and for most of the patients, determination of HLA-B haplotype was not available in routine practice. "Clinical hypersensitivity" as defined by the physician, as well as "cutaneous intolerance" and "treatment intolerance" was all considered as suspected HSR. If a patient died while taking ABC/3TC, the date of death was recorded as date of discontinuation. The cause of death was collected for each patient. In the event of unknown cause of death, it was considered as potentially related with a major cardio-vascular event (CVE). Major CVEs were defined as myocardial infarction, stroke, and surgery for coronary artery disease or unwitnessed death. Minor events were defined as peripheral vascular disease, congestive heart failure or drug treatment for coronary artery disease. All CVEs recorded while a patient was receiving $\mathrm{ABC} / 3 \mathrm{TC}$ were analyzed regardless of their severity. Virological success was defined as a VL below 50 copies $/ \mathrm{mL}$.

All analyses were carried out on the overall population and in the 3 defined groups (naïve, switch and failure). Categorical variables were described by frequencies and numerical variables by distribution (median, 25 and 75\% percentiles). Time to treatment discontinuation was analyzed by the Kaplan Meier survival method. Follow-up was censored if the patient stopped taking $\mathrm{ABC} / 3 \mathrm{TC}$, died or at the censoring date (31 may 2008) whichever occurred first. If the patient was lost to follow up, the last date of medical visit was considered as date of last news. Statistical analyses were performed with the use of SAS software version 9.1 (SAS Institute, NC, and USA).

\section{Results}

We identified 1704 patients who responded to the selection criteria. $\mathrm{ABC} / 3 \mathrm{TC}$ was used as part of the first regimen for 407 patients

\begin{tabular}{|c|c|c|c|c|}
\hline & Naïve patients ( $\mathrm{N}=407)$ & Switch $(\mathrm{N}=696)$ & Failure $(\mathrm{N}=601)$ & Total $(\mathrm{N}=1704)$ \\
\hline Sex, N (\%) men & $295(72.5)$ & $483(69.4)$ & $398(66.2)$ & $1176(69)$ \\
\hline Age, median [Q1-Q3] years & $41[23.5-48]$ & $44[38-50]$ & 42 [36-48] & 43 [36-49] \\
\hline Lenght of known infection, median [Q1-Q3] years & $2[0.3-7.8]$ & $9.2[4-14.6]$ & $11.5[6.6-16]$ & 8.7 [2.9-14.5] \\
\hline Hepatitis co-infection, N (\%) & $83(20.4)$ & $161(23.1)$ & $167(27.8)$ & $411(24.1)$ \\
\hline Previous CDC class $\mathrm{C}$ event, $\mathrm{N}(\%)$ & $85(20.9)$ & $209(30)$ & $179(29.8)$ & $473(27.8)$ \\
\hline Baseline VL, median [Q1-Q3] $\log _{10}$ copies $/ \mathrm{mL}$ & $4.8[4.1-5.3]$ & $1.6[1.6-1.6]$ & $3.9[2.6-4.8]$ & $2.5[1.7-4.5]$ \\
\hline Patients with baseline VL $\geq 5 \log _{10}$ copies/mL (\%) & 41.2 & - & 18.5 & 15.1 \\
\hline Baseline CD4 cells/mm³, median [Q1-Q3] & $239,2[111-319]$ & $512,4[345-670]$ & $286[167-456]$ & $354,7[211-558]$ \\
\hline Baseline CD4 cells <200/mm ${ }^{3}(\%)$ & 40.4 & 8.1 & 30.8 & 23 \\
\hline Nadir CD4 cells/mm³, median [Q1-Q3] & 222 [104-289] & 177 [71-264] & 174 [64-261] & $184[74-272]$ \\
\hline Number of previous regimens, median [Q1-Q3] & - & $3[1-5]$ & 3 [2-5] & 3 [3-5] \\
\hline \multicolumn{5}{|l|}{ Treatment strategies } \\
\hline 3 drugs in the regimen, $\mathrm{N}(\%)$ & $373(92)$ & $664(95)$ & $485(81)$ & $1522(89)$ \\
\hline ABC/3TC + 1 NNRTI, N (\%) & $36(9)$ & $241(35)$ & $49(8)$ & $326(19)$ \\
\hline $\mathrm{ABC} / 3 \mathrm{TC}+1 \mathrm{bPI}, \mathrm{N}(\%)$ & $211(52)$ & $279(40)$ & $301(50)$ & $791(46)$ \\
\hline $\mathrm{ABC} / 3 \mathrm{TC}+\mathrm{AZT}, \mathrm{N}(\%)$ & $119(29)$ & $115(16)$ & $117(19.5)$ & $351(21)$ \\
\hline Other, N (\%) & $7(2)$ & $29(4)$ & $18(3.5)$ & $54(3)$ \\
\hline 4 drugs or more in the regimen, $N(\%)$ & $32(8)$ & $26(4)$ & $113(19)$ & $171(10)$ \\
\hline
\end{tabular}

"Naïve patients": ABC/3TC used as part of the first regimen, "switch": as part of a switch strategy in patients with VL below detection, "failure" as part of a rescue regimen in patients with a previous failing regimen; VL=viral load 
(naïve group), as part of a switch strategy in 696 patients with VL below detection) and as part of a salvage regimen in 601 patients with a previous failing regimen (failure). Patients were men in $69 \%$ of the cases, median age 43 years, with $23 \%$ of the population over 50 year-old. Population characteristics at baseline are shown in Table $1 . \mathrm{ABC} / 3 \mathrm{TC}$ fixed dose combinations were used in $78 \%$ of the patients, the median CD4 cell count was lower in the naïve population $\left(239\right.$ cells $\left./ \mathrm{mm}^{3}\right)$ than compared to the other groups and $41 \%$ had a median viral load above $5 \log _{10}$ copies $/ \mathrm{mL}$. The regimen contained 3 drugs in $92 \%$ of the naïve, $95 \%$ of the switch and $81 \%$ of failure groups. A boosted PI was the $3^{\text {rd }}$ agent associated with $\mathrm{ABC} / 3 \mathrm{TC}$ in $46 \%$ of the overall population, $52 \%$, $40 \%$ and $50 \%$ respectively in the naive, switched and failure population (details on the treatment regimen are shown in Table 1).

Among all the population $(n=1704)$, the median time to treatment discontinuation using the Kaplan Meier survival method was 52 months with differences related to the reason for discontinuation (Figure 1). After 2 years of follow up, 62\%, 77\% and $60 \%$ of the naïve, switch and failure population respectively were still taking ABC/3TC.

Overall, 565 treatment discontinuations were recorded $(33 \%$ of the population). In the naïve, switch and failure populations, the proportions were respectively $36 \%, 24 \%$ and $42 \%$. Median time [IQR] before discontinuation was respectively 4 [1.1-10.2], 4.8 [1.113.8] and 7.3 [1.2-17.7] months in the naïve, switch and failure populations $(\mathrm{p}=0.067)$. Details of reasons for discontinuation are shown in Table 2. Consistently across the groups, the most frequent reason for discontinuation was intolerance representing $14 \%$ of the total population $(14 \%, 13 \%$, and $15 \%$ of the naive, switch and failure populations). HSR was clinically suspected in $4 \%$ of the patients. Most discontinuations for tolerability reasons (respectively $84 \%, 75 \%$, and $74 \%$ across the groups) occurred during the first 6 months. In the event of suspected HSR, median time before discontinuation was of
17 days [10-33] and for the other tolerability reasons the median time was more than 3 months. No difference in frequency of treatment discontinuation for tolerance was described depending on the other drugs contained in the regimen: $13 \%$ of the 791 patients receiving a ritonavir boosted protease inhibitor (bPI) and $12 \%$ of the 326 patients receiving a non nucleosidic transcriptase inhibitor (NNRTI). Among the treatment naïve population, discontinuation for virological failure was recorded in 5 (3\%) patients out of the 168 with $\mathrm{VL} \geq 5 \log _{10}$ copies/ $\mathrm{ml}$ and in 11 (4.6\%) of the 239 others patients. After $\mathrm{ABC} / 3 \mathrm{TC}$ regimen discontinuation, $\mathrm{ABC}$ was found in the subsequent regimen for $26 \%$ of these patients.

Death was recorded in 27 patients: 9 were AIDS related, 6 due to an end stage liver disease, 6 to cancers, 1 to myocardial infarction, 1 to neurological vascular event, 1 to car fatality and 3 of unknown causes.

A CVE was recorded in 58 patients out of the overall population. Out of these, 21 patients presented a major CVE so the calculated incidence was 8/1000 patients-year - including 12 myocardial infarctions, incidence 5/1000 patient-year. Among these 21 patients, 20 were male with a median age 49 years, 5 had a previous CVE in their medical history, 1 died due to myocardial infarction and 3 were un-witnessed deaths, viral load was below detection for 12, 2 patients were receiving $\mathrm{ABC} / 3 \mathrm{TC}$ as part as their first regimen, 13 had been receiving $\mathrm{ABC} / 3 \mathrm{TC}$ for more than 1 year, 20 had been treated with a $\mathrm{PI}$-containing regimen before the major CVE occurrence and 4 had a detectable viral load and $581 / \mathrm{mm}^{3} \mathrm{CD} 4$ cells count before the event.

Proportions of patients with virological success at different time points are shown in Figure 2. After 2 years, $86 \%, 90 \%$, and $70 \%$ of the naïve, switch and failure groups, respectively had a viral load below 50 copies $/ \mathrm{mL}$. The virological success in the naïve group according to viral load $<$ or $>5 \log _{10}$ copies/mL tends to show a lesser response in the group of patient with a high viral load. The results are in line with what
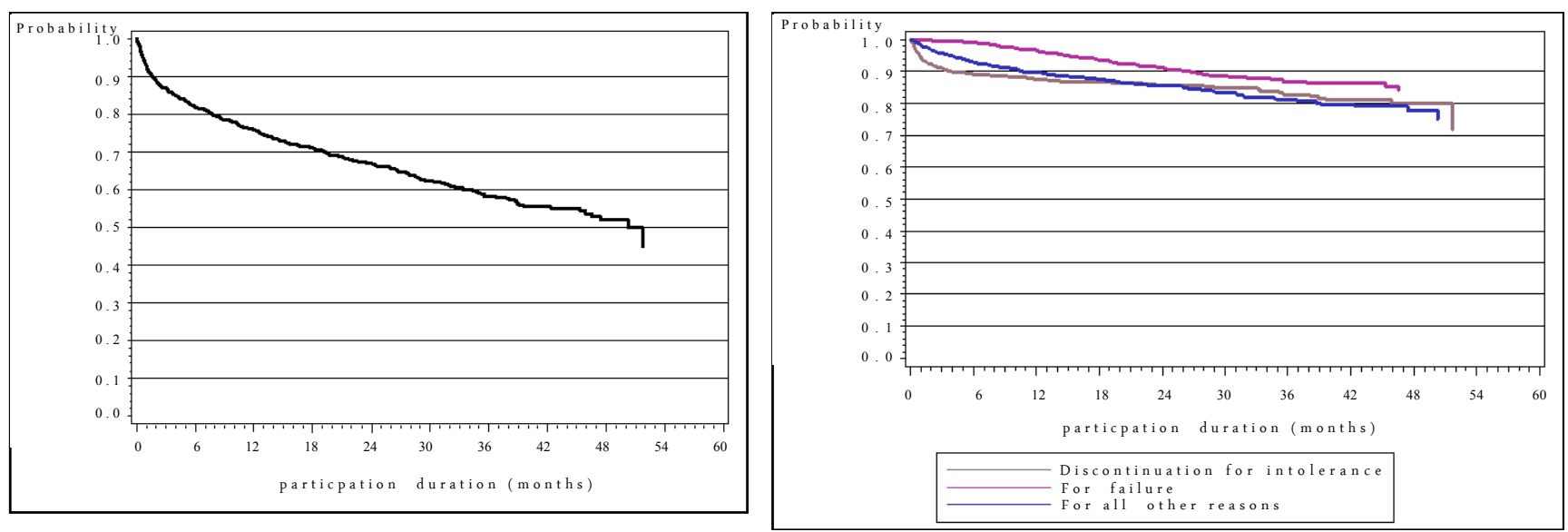

Figure 1: Time to treatment discontinuation overall (1A) and by major reason for discontinuation (1B).

\begin{tabular}{|c|c|c|c|c|c|c|c|c|c|}
\hline \multirow[b]{2}{*}{$\begin{array}{l}\text { Treatment duration before discon- } \\
\text { tinuation }\end{array}$} & \multicolumn{3}{|c|}{ Naïve patients $(\mathrm{N}=407)$} & \multicolumn{3}{|c|}{ Switch (N=696) } & \multicolumn{3}{|c|}{ Failure $(\mathrm{N}=601)$} \\
\hline & $\begin{array}{l}{[0-6[} \\
\text { months } \\
(\mathrm{N}=93)\end{array}$ & $\begin{array}{l}\geq 6 \text { months } \\
(\mathrm{N}=55)\end{array}$ & $\begin{array}{l}\text { Total } \\
(\mathrm{N}=148)\end{array}$ & $\begin{array}{l}{[0-6[\text { months }} \\
(\mathrm{N}=93)\end{array}$ & $\begin{array}{l}\geq 6 \text { months } \\
(\mathrm{N}=73)\end{array}$ & Total $(\mathrm{N}=166)$ & $\begin{array}{l}{[0-6[\text { months }} \\
(\mathrm{N}=120)\end{array}$ & $\begin{array}{l}\geq 6 \text { months } \\
(\mathrm{N}=131)\end{array}$ & Total $(\mathrm{N}=\mathbf{2 5 1})$ \\
\hline Intolerance, N (\%) & $47(11.5)$ & $9(2.5)$ & $56(14)$ & $68(10)$ & $22(3)$ & $90(13)$ & $65(11)$ & $23(4)$ & $88(15)$ \\
\hline Suspected hypersensitivity, N (\%) & $27(6.6)$ & $3(0.7)$ & $30(7.3)$ & $40(5.7)$ & $2(0.3)$ & $42(6)$ & $46(7.6)$ & $2(0.3)$ & $48(7.9)$ \\
\hline Treatment failure, $\mathrm{N}(\%)$ & $6(2)$ & $17(4)$ & $23(6)$ & $2(1)$ & $16(2)$ & $18(3)$ & $7(1)$ & $66(11)$ & $73(12)$ \\
\hline Other, including non adherence, $\mathrm{N}(\%)$ & $40(10)$ & $29(7)$ & $69(17)$ & $23(3.3)$ & $35(5)$ & $58(8.3)$ & $48(8)$ & $42(7)$ & $90(15)$ \\
\hline
\end{tabular}

Table 2: Reasons for treatment discontinuation across the groups and the treatment duration. 


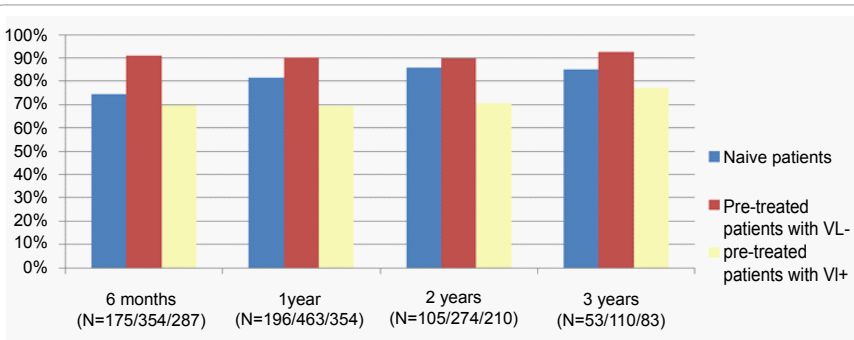

Figure 2: Proportion of patients with VL below 50 copies $/ \mathrm{mL}$ for the naïve switch, and failure groups, restricted to patients with available data (ITT).

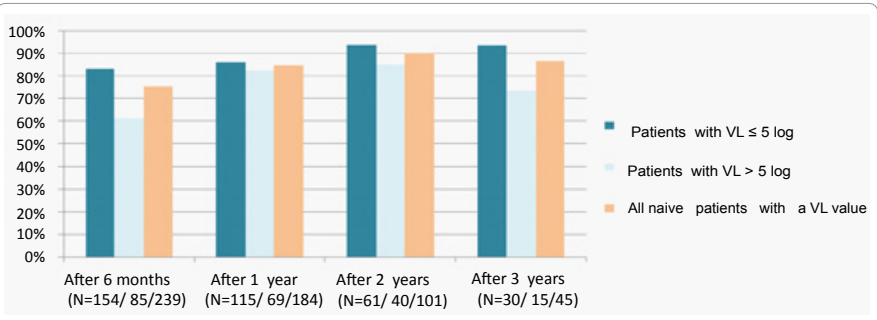

Figure 3: Proportion of patients with $\mathrm{VL}$ below $50 \mathrm{copies} / \mathrm{mL}$ for the naïve group, according to $\mathrm{VL}$ before initiation of $\mathrm{ABC} / 3 \mathrm{TC}$ (LOCF).

a lot of clinical trials have shown with different drugs regimens in this group of patient (Figure 3).

\section{Discussion}

In this population receiving $\mathrm{ABC} / 3 \mathrm{TC}$ before $\mathrm{HLA}-\mathrm{B}^{\star} 5701$ screening was routinely available, we report that cART containing $\mathrm{ABC} / 3 \mathrm{TC}$ in association with at least one other ARV was maintained for a median time of 52 months in the overall population. For the $565(33 \%)$ patients in whom treatment was discontinued, the median time before discontinuation was 4 months in the patients receiving $\mathrm{ABC} / 3 \mathrm{TC}$ as part of their first cART, 5 months in patients receiving it as a switch strategy and 7 months in those receiving it following previous virological failure. After two years, $62 \%, 77 \%$ and $60 \%$ of the same groups were still on $\mathrm{ABC} / 3 \mathrm{TC}$ treatment. This duration is longer than previously described in the Swiss cohort [9] in which $45 \%$ of the patients underwent treatment discontinuation during the first year of therapy. No difference was observed when $\mathrm{ABC} / 3 \mathrm{TC}$ was combined with either a bPI or a NNRTI in naïve or in pretreated patients, a different result was seen in ACTG5202 where a shorter "time-to-safety" event and regimen change were seen in the Efavirenz group compared to the boosted Atazanavir group but this difference could be due to the definition of safety endpoint composite of laboratory and clinical adverse events as well as the low frequency of genotype resistance testing before ABC/3TC initiation (43 to 48\%) [7]. The most frequent reason for discontinuation across the population was intolerance occurring in $14 \%$ of the overall population. HSR was clinically suspected in $4 \%$ of the patients. This frequency is lower than that described in the control group of the PREDICT-1 study, defining the predictive value of HLA-B ${ }^{\star} 5701$ testing, were it was suspected in $7.8 \%$ of the patients. Median time to suspected HSR was longer (17 days) than described in PREDICT-1 (average time to onset of HSR symptoms of 9 days) [3]. This difference is possibly due to subjective definition of HSR and/or to data collection methods with possible memory bias if the treatment discontinuation date is retrospectively collected at the time of the next medical visit.

Discontinuation due to virological failure was infrequent as previously described in various populations of naïve or pretreated patients [10-14]. With an "on treatment" basis at two years, virological control was observed in our cohort in more than $80 \%$ of the naïve and switch patients and in around $70 \%$ of the patients with previous virological failures, comparing favorably with the results of the naïve patients of the HEAT study evaluating ABC/3TC versus tenofovir/ emtricitabine (TDF/FTC) in patients receiving boosted lopinavir as third agent [15]. Cardiovascular events were as rare as previously described [16]. However, information on some risk factors were lacking such as smoking status, fasting lipid levels or measurement of blood pressure to analyze it more precisely and a more adaptive methodology including a comparison group would have been better. It is noteworthy that at the beginning of our study, cART that included a protease inhibitor was assumed to be associated with metabolic abnormalities that could increase the risk of cardiovascular disease [17,18]. ABC in association with nucleosidic reverse transcriptase inhibitors have been shown to cause a greater decrease in plasma lipid levels than did nevirapine or efavirenz [19]. These data may be responsible for a sort of channeling bias regarding $\mathrm{ABC}$ prescription in patients with cardio-vascular risk factors that were known to the physician but not registered in our database. Other recent studies have shown that potential confounders could exist as e.g. cocaine use or kidney disease and most analyses that control for known risk factors did not support the increased risk of MI due to $\mathrm{ABC}$ [5].

Finally, in this real-life large population, duration of treatment tolerability (all discontinuation causes combined) compares favorably with that reported in the randomized ACTG 5202 study comparing $\mathrm{ABC} / 3 \mathrm{TC}$ with $\mathrm{TDF} / \mathrm{FTC}$ containing regimens in antiretroviral naive patients [7].

The observational prospective design of our study resulted in some limitations. For example, we do not collect any quantified adherence information nor up-to-date smoking habits so we are unable to provide some potentially useful information. However, long term studies including large and varied populations are difficult to carry out and yet; cohorts do provide valuable information as long as the potential biases are taken into account [20].

\section{Conclusion}

In this large cohort that is, to our knowledge, the first to report long-term use of $\mathrm{ABC} / 3 \mathrm{TC}$ in clinical settings, we report good long term tolerability of the combination. Since HLA-B ${ }^{\star} 5701$ screening has been proven to significantly reduce HSR suspicion, we believe that our results may be useful. Once short term tolerance problems were resolved, long term side effects were infrequent. The use of well tolerated drugs is a mean for providing long term adherence and efficacy.

\section{Acknowledgement}

The authors thank Nathalie Texier (Kappa Santé) for her contribution in the analysis of this study.

\section{References}

1. Katlama C, Clotet B, Plettenberg A, Jost J, Arasteh K, et al. (2000) The role of abacavir (ABC, 1592) in antiretroviral therapy-experienced patients: results from a randomized, double-blind, trial. CNA3002 European Study Team. AIDS 14: 781-789.

2. Hetherington S, McGuirk S, Powell G, Cutrell A, Naderer O, et al. (2001) Hypersensitivity reactions during therapy with the nucleoside reverse transcriptase inhibitor abacavir. Clin Ther 23: 1603-1614.

3. Mallal S, Phillips E, Carosi G, Molina JM, Workman C, et al. (2008) HLA-B*570 screening for hypersensitivity to abacavir. N Engl J Med 358: 568-579. 
Citation: Cuzin L, Allavena C, Finkielsztejn L, Melliez H, Pugliese P, et al. (2012) Tolerance and Durability of Abacavir/Lamivudine (ABC/3TC) Containing Regimens: Results from a large French Prospective Cohort. J AIDS Clinic Res S1:019. doi:10.4172/2155-6113.S1-019

Page 5 of 5

4. Strategies for Management of Anti-Retroviral Therapy/INSIGHT; DAD Study Groups (2008) Use of nucleoside reverse transcriptase inhibitors and risk of myocardial infarction in HIV-infected patients. AIDS 22: F17-24.

5. Lang S, Mary-Krause M, Cotte L, Gilquin J, Partisani M, et al. (2010) Impact of individual antiretroviral drugs on the risk of myocardial infarction in human immunodeficiency virus-infected patients: a case-control study nested within the French Hospital Database on HIV ANRS cohort CO4. Arch Intern Med 170: 1228-1238.

6. Ding X, Andraca-Carrera E, Cooper C, Miele P, Kornegay C, et al. (2011) No Association of Myocardial Infarction with Abacavir Use: Findings of an FDA Meta-analysis. Poster 808, 18th Conference on Retrovirus and Opportunistic Infection, Boston.

7. Daar ES, Tierney C, Fischl MA, Sax PE, Mollan K, et al. (2011) Atazanavir Plus Ritonavir or Efavirenz as Part of a 3-Drug Regimen for Initial Treatment of HIV1. Ann Intern Med 154: 445-456.

8. Pugliese P, Cuzin L, Cabié A, Poizot-Martin I, Allavena C, et al. (2009) A large French prospective cohort of HIV-infected patients: the Nadis Cohort. HIV Med 10: $504-511$

9. Opravil M, Baumann D, Chave JP, Furrer H, Calmy A, et al. (2004) Long-term efficacy after switch from protease inhibitor-containing highly active antiretroviral therapy to abacavir, lamivudine, and zidovudine. AIDS 18: 2213-2215.

10. Arastéh K, Yeni P, Pozniak A, Grinsztejn B, Jayaweera D, et al. (2009) Efficacy and safety of darunavir/ritonavir in treatment-experienced HIV type-1 patients in the POWER 1, 2 and 3 trials at week 96. Antivir Ther 14: 859-864.

11. Gatell JM, Katlama C, Grinsztejn B, Eron JJ, Lazzarin A, et al. (2010) Long term efficacy and safety of the HIV integrase inhibitor raltegravir in patients with limited treatment options in a Phase II study. J Acquir Immune Defic Syndr. 53: $456-463$

12. Post FA, Moyle GJ, Stellbrink HJ, Domingo P, Podzamczer D, et al. (2010) Randomized comparison of renal effects, efficacy, and safety with oncedaily abacavir/lamivudine versus tenofovir/emtricitabine, administered with efavirenz, in antiretroviral-naive, HIV-1-infected adults: 48-week results from the ASSERT study. J Acquir Immune Defic Syndr 55: 49-57.

13. Pulido F, Estrada V, Baril JG, Logue K, Schewe K, et al. (2009) Long-term efficacy and safety of fosamprenavir plus ritonavir versus lopinavir/ritonavir in combination with abacavir/lamivudine over 144 weeks. HIV Clin Trials 10: 7687.

14. Steigbigel RT, Cooper DA, Teppler H, Eron JJ, Gatell JM, et al. (2010) Long term efficacy and safety of Raltegravir combined with optimized background therapy in treatment-experienced patients with drug-resistant HIV infection: week 96 results of the BENCHMRK 1 and 2 Phase III trials. Clin Infect Dis 50 605-612.

15. Smith KY, Patel P, Fine D, Bellos N, Sloan L, et al. (2009) Randomized, doubleblind, placebo-matched, multicenter trial of abacavir/lamivudine or tenofovir/ emtricitabine with lopinavir/ritonavir for initial HIV treatment. AIDS 23: 15471556.

16. Currier JS, Lundgren JD, Carr A, Klein D, Sabin CA, et al. (2008) Epidemiological evidence for cardiovascular disease in HIV-infected patients and relationship to highly active antiretroviral therapy. Circulation 118: e29-35.

17. Holmberg SD, Moorman AC, Williamson JM, Tong TC, Ward DJ, et al. (2002) Protease inhibitors and cardiovascular outcomes in patients with HIV-1. Lance 360: $1747-1748$

18. Mary-Krause M, Cotte L, Simon A, Partisani M, Costagliola D (2003) Increased risk of myocardial infarction with duration of protease inhibitor therapy in HIVinfected men. AIDS 17: 2479-2486.

19. Martínez E, Arnaiz JA, Podzamczer D, Dalmau D, Ribera E, et al. (2003) Substitution of nevirapine, efavirenz, or abacavir for protease inhibitors in patients with human immunodeficiency virus infection. N Engl J Med 349: 10361046.

20. Phillips AN, Grabar S, Tassie JM, Costagliola D, Lundgren JD, et al. (1999) Use of observational databases to evaluate the effectiveness of antiretrovira therapy for HIV infection: comparison of cohort studies with randomized trials. EuroSIDA, the French Hospital Database on HIV and the Swiss HIV Cohor Study Groups. AIDS 13: 2075-2082.

21. Cruciani M, Zanichelli V, Serpelloni G, Bosco O, Malena M, et al. (2011) Abacavir use and Cardiovascular Disease Events: a meta-analysis of published and unpublished data. AIDS 25: 1993-2004.

22. Brothers $\mathrm{CH}$, Hernandez JE, Cutrell AG, Curtis L, Ait-Khaled M, et al. (2009) Risk of Myocardial Infarction and Abacavir Therapy: No Increased Risk Across 52 GlaxoSmithKline-Sponsored Clinical Trials in Adult Subjects. J Acquir Immune Defic Syndr 51: 20-28. 